\title{
Comorbidity patterns in adolescents and young adults with suicide attempts
}

\author{
U. Wunderlich · T. Bronisch · H.-U. Wittchen
}

Received: 17 July 1997 / Accepted: 15 December 1997

\begin{abstract}
The role of comorbidity as a risk for suicide attempts is investigated in a random sample of 3021 young adults aged 14-24 years. The M-CIDI, a fully standardized and modified version of the Composite International Diagnostic Interview, was used for the assessment of various DSM-IV lifetime and 12-month diagnoses as well as suicidal ideation and suicide attempts. Of all suicide attempters, $91 \%$ had at least one mental disorder, $79 \%$ were comorbid or multimorbid respectively and $45 \%$ had four or more diagnoses (only 5\% in the total sample reached such high levels of comorbidity). Suicide attempters with more than three diagnoses were 18 times more likely (OR = 18.4) to attempt suicide than subjects with no diagnosis. Regarding specific diagnoses, multivariate comorbidity analyses indicated the highest risk for suicide attempt in those suffering from anxiety disorder $(\mathrm{OR}=4.3$ ), particularly posttraumatic stress disorder followed by substance disorder $(\mathrm{OR}=$ 2.2 ) and depressive disorder (OR = 2.1). Comorbidity, especially when anxiety disorders are involved, increases the risk for suicide attempts considerably more than any other individual DSM-IV diagnoses.
\end{abstract}

Key words: Suicide attempt, Comorbidity, Mental disorders, Adolescents, Epidemiology

\section{Introduction}

Suicide attempts in adolescents and young adults are a serious health problem in industrialized countries. Estimates of the lifetime risk of suicide attempts reported in community studies have ranged from 2.2 to $7.1 \%$ in response to structured interviews (Lewis et al. 1988; Kienhorst et al. 1995; Andrews and Lewinsohn 1992; Bronisch and Wittchen 1994) to 6 to 9\% for high school students' selfreport data (Smith and Crawford 1986; Harkavy Friedman et al. 1987; Dubow et al. 1989; Shaffer et al. 1990). In many European countries, as well as in highly industrialized countries in other parts of the world, the overall suicide rate seems to have risen over the past two decades (Diekstra 1993). In fact, it is speculated that the rise in the overall suicide rates in many countries might be due, to a large extent, to the increase in suicides in younger age groups. Even countries with a stable or decreasing overall suicide rate still witness increasing rates in the young (Kienhorst et al. 1995). There is strong evidence from long-term follow-up studies that suicide attempt is a powerful predictor of suicide (Bronisch 1992), whereby suicide attempts occur at least two to three times more often than suicides (Schmidtke et al. 1996). Therefore, the detection of predictors of suicide attempts is of great clinical importance. Among the long list of factors found to be associated with suicide attempts (Spirito et al. 1989), one particularly interesting, yet controversial, topic is the question to what degree psychopathological features, such as depressive disorders, are a key antecedent of suicide attempts. At first sight, the picture seems to be clear: depressive disorders are often and fairly consistently cited in the literature as a risk factor for suicide attempt (Andrews and Lewinsohn 1992; Brent et al. 1993; Breslau et al. 1991; Garrison et al. 1993; Garnefski and Diekstra 1995; Levy and Deykin 1989; Lewis et al. 1988; Joffe et al. 1988; Velez and Cohen 1988). There are also several studies suggesting that substance disorders, as well as other psychopathological syndromes, might be related to suicide attempts (Andrews and Lewinsohn 1992; Bronisch and Wittchen 1994; Breslau et al. 1991; Garrison et al. 1993; Levy and Deykin 1989; Velez and Cohen 1988). Among studies 
evaluating suicidal behaviour in adolescents, also, few have assessed suicidal behaviour and its relationship to psychopathological syndromes using strict epidemiological methods (Velez and Cohen 1988; Joffe et al. 1988; Levy and Deykin 1989; Breslau et al. 1991; Andrews and Lewinsohn 1992; Garnefski and Diekstra 1995). Nevertheless the study by Lewinsohn et al. (1995b) is the only one, to our knowledge, that explores comorbidity of psychiatric disorders in connection with suicide attempts. They compared subjects in a community sample of 1507 adolescents (aged 14-18 years) with "pure" and comorbid forms of four major psychiatric disorders (depression, anxiety, substance use, and disruptive behaviour) on six clinical outcome measures (past suicide attempts, academic problems, mental health treatment utilization, role functioning, conflict with parents, physical symptoms). The rates of past suicide attempts, one of six different outcome measures, significantly increased as a function of the number of disorders. Subjects with multiple comorbid disorders had a greater rate of suicide attempts than those with two disorders. Johnson et al. (1990) demonstrated a strong association between panic disorder and suicide attempts based on data from the Epidemiologic Catchment Area study (a probability sample of more than 18000 adults living in five U.S. communities). For panic disorder compared with no disorder, the odds ratio was 5.4 for uncomplicated and 22.8 for comorbid in comparison with major depression with 5.1 and 17.3, respectively. A similar finding was confirmed by Bronisch and Wittchen (1994) who investigated the effect of comorbidity on rates of suicidal ideation and suicide attempts from an adult general population of former West Germany. They found the highest odds ratios for suicide attempters with major depression comorbid with panic attack (OR =12.6) or substance abuse disorder $(\mathrm{OR}=14.6)$. Subjects with pure major depression did not display a significantly elevated odds ratio. Breslau et al. (1991) investigated 1007 21- to 30-year-old members of a large Health Maintenance Organization (HMO). The primary objective of this study was the assessment of comorbidity with migraine. A logistical regression analysis revealed a coexistence of migraine with major depression, anxiety disorders and suicide attempts. Thus, there is some evidence that not depressive disorders per se but rather comorbidity, particularly with anxiety disorders, plays a significant role in suicide attempts. In an attempt to further clarify these issues, this paper examines the following questions in a community sample of young adults (aged 14-24 years): 1 . How frequent are suicidal ideation and suicide attempts in adolescents and young adults? 2. With what type of mental disorders are suicide attempts associated with in adolescence? 3. Which types of comorbidity patterns are associated with the increased risk for suicide attempts in adolescents and young adults?

\section{Methods}

The data presented here are from the first wave of the Early Developmental Stages of Psychopathology study (EDSP), funded by the German Ministry of Research and Technology. The study is designed to collect data on the prevalence, risk factors, comorbidity and course of mental disorders with specific emphasis on early developmental stages of mental disorders, including substance use disorders. The overall design of the study is prospective, consisting of a baseline survey and two follow-up surveys at approximately 15 and 30 months after the baseline. Separate personal interviews with a subgroup of the respondents' parents are currently being carried out. The follow-up assessments investigate symptom and syndrome progression, incidence and remission, as well as helpseeking and the development of impairments.

\section{Sample}


The sample was drawn from 1994 government registries of all residents in metropolitan Munich (1990 population 3.2 million; Statistisches Jahrbuch 1994) expected to be 14-24 years of age at the time of interview during the first half of 1995. Because the study is designed as a longitudinal panel with special interest in the development of substance use disorders, 14-15 year olds were sampled at twice the rate of persons 16-20 years of age, and 21- to 24-yearolds were sampled at nearly half this rate. The results presented here are from the first wave of data collection which was conducted from January 1995 to July 1995. From the total of 4809 sampled individuals, 4263 were located and determined to be eligible for the study. Sampled individuals who were not located were disproportionately older and uncontactable because they either (a) had moved outside the metropolitan area in the time interval between their registration and the beginning of the study in 1995 (8.8\%), or (b) could not be associated with the listed address during the field work period (2.4\%). Among the listed individuals, a total of 3021 interviews were completed resulting in a response rate of $71 \%$. Refusal to participate (18.2\%) was by far the most frequent reason for non-response among located individuals followed by lack of time (3.3\%) and failure to contact anyone in the identified household (3.0\%). Among individuals who were successfully located, a preliminary analysis comparing non-respondents to respondents shows that non-response increased with age, especially among women, whose non-response rates were slightly higher than those of men among individuals 18+ years of age. The slightly higher proportion of refusals among women was due to increased reports of lack of time, failure to contact anyone in the household and failure to contact the sampled individual. To account for the oversampling of persons expected to be 14-15 years of age at interview and for the individuals who were not located and non-response, the data has been adjusted for age, gender and geographic location to match the distribution of the sampling frame. Table 2 shows the distribution of sociodemographic variables in the sample. Roughly one third of the sample falls into each of the three age categories of 14-17, 18-21 and 22-24 years. As can be seen, approximately two thirds of the sample is currently attending or has attended "Gymnasium" (secondary education which prepares students for possible entrance into university) or university and is currently living with their parents. Twenty-three percent of the sample is living alone or with friends. Whereas approximately two thirds of the sample perceives their financial situation as good or very good, and another $28.0 \%$ see it as neither good nor bad, $8.2 \%$ see it as bad or very bad. Of the sample, $7.6 \%$ stated that they belong to the lower social class, $59.1 \%$ to the middle and $31.4 \%$ to the upper social class. Of the sample, $24.9 \%$ reported that their parents are separated or divorced, and $18.1 \%$ were not raised by both parents. Of the sample, 5.0\% reported their father's death and only $2.2 \%$ their mother's death.

\section{Diagnostic assessment}

Psychopathological and diagnostic assessments were based on the Munich version of the Composite International Diagnostic Interview (M-CIDI; Wittchen and Pfister 1997, Wittchen et al. 1995, 1998). The M-CIDI is an updated version of the World Health Organization (WHO) CIDI version 1.2 (supplemented by questions from WHO-CIDI version 2.0 developed to cover DSM-IV and ICD-10 criteria (Wittchen and Pfister 1997). The M-CIDI evaluates a broader range of diagnoses and syndromes than previous versions of the CIDI and incorporates memory aid techniques introduced by the National Comorbidity Survey (NCS; Kessler et al. 1994) to improve the recall of past events. The M-CIDI allows for the assessment of symptoms, syndromes and diagnoses of 48 mental disorders (not counting various subtypes of main disorders) along with information about onset, duration, and clinical and psychosocial severity. Diagnostic analysis is based on the M-CIDI diagnostic package “DSM-IV diagnostic algorithms” (Pfister and Wittchen 1995). 
The survey staff was highly experienced and consisted of ten clinical interviewers and fulltime professional health research interviewers from "Infratest-Gesundheitsforschung”, a survey company specializing in health interview research. The clinical interviewers consisted of ten clinical psychologists in postgraduate education for being licensed clinical psychologists. Most of these already had extensive experience in diagnostic interviewing including the application of the CIDI as well as the developmental work of the M-CIDI. All interviewers received two full weeks of training in use of the study instrument including the CIDI standard training components. For a more detailed description of interviewer training and supervision see Wittchen et al. (in press).

\section{Evaluation of psychopathology and diagnoses}

All DSM-IV diagnostic categories derived from the M-CIDI that included at least 4 subjects who had attempted suicide at any time in their life were included in the analyses. Thus, the focus of interest was not only on affective disorders, anxiety disorders and substance use disorders, which were shown to be associated with suicidal behaviour in previous studies (Bronisch and Wittchen 1994), but also on somatoform disorders (undifferentiated somatization disorder and pain disorder) and eating disorder. The following questions regarding suicidal ideation and suicidal behaviour were used for the analyses: 1. E35: Has there ever been a period of 2 weeks or more when you thought a lot about death, either your own, someone else's or death in general? 2. E36: Has there been a period of 2 weeks or more when you felt like you wanted to die? 3. E37: Have you ever felt so low that you thought about committing suicide? 4. E37A: Have you ever made a plan as to how you might do it? 5. E38: Have you ever attempted suicide?

\section{Statistical analysis}

Prevalence rates and odds ratios were computed from weighted data. Weights used refer to the stratification described previously. Adjusted odds ratios with 95\% confidence intervals (95\% CI) were calculated by logistical regression analysis using the SPSS (Statistical Package for Social Sciences) software package (1997). The ratios indicate the strength of the association between the diagnostic groups and the suicide-related variables. The statistical significance of the adjusted odds ratios can be judged from the confidence intervals (whether the interval excludes 1.0). A confidence interval that includes 1.0 indicates no statistical evidence for excess risk for the diagnostic group. A confidence interval higher than 1.0 indicates increased risk for suicidal ideation and suicide attempts. To uncover main predictor variables (diagnoses) of suicide attempt, a multivariate logistic regression analysis using the "enter" procedure was used. All the significant univariate variables were fit into the multivariate analysis to define the statistical power of each of the variables with consideration of the interaction effects.

\section{Results}

Prevalence rates of suicidal ideation and suicide attempts

Table 1 shows that $2.3 \%$ of the total sample reported having attempted suicide at some point in their life, women more frequently (3.1\%) than men (1.5\%). Of the sample, $10.2 \%$ had suicidal ideation, but only $6.8 \%$ of the total sample had the wish to die. One fifth of the 
sample (19.6\%) thought about death, either about death in general, about their own death or about the death of another person for 2 weeks or more. In each of these five categories women show higher rates than men.

\section{Sociodemographic correlates of suicide attempt}

Women between the ages of 14 and 17 (30.8\%; OR $=1.7$; $\mathrm{P}<0.05$ ) are much more likely to report suicide attempts than men in this age group (10.8\%). Whereas suicide attempt rates in females were almost identical in all age groups, there are considerably fewer male suicide attempters in the youngest age group (Table 2). Univariate analyses revealed several additional associations with suicide attempt. Among these are a moderate risk for lower educational status ("Hauptschule": highest degree basic school; OR $=2.0, \mathrm{P}<0.05$ ), and a notably high OR of 41.7 was found for school dropouts, i.e. those who either did not finish school or received special education for the disadvantaged. Low socioeconomic status (OR = 2.8, $\mathrm{P}<0.001)$ and subjectively perceived bad financial situation $(\mathrm{OR}=2.2, \mathrm{P}<0.05)$ were moderately associated with suicide attempts. Parents of suicide attempters are more often separated or divorced than parents of repondents $(\mathrm{OR}=4.1)$. Of the suicide attempters, $40.7 \%$ $(\mathrm{OR}=2.9)$ were raised by a single parent compared with only $18.1 \%$ in the total sample. A multivariate summary analysis of all significant variables in the univariate examination revealed four significant ORs: (a) school dropout (OR = 37.1, P < 0.001; 95\% CI: 5.1-268.2; $\mathrm{n}=4$ ); (b) parents separated or divorced (OR = 3.2, P < 0.001; 95\% CI: 1.8-5.9); (c) lower social class (OR = 2.4; $\mathrm{P}<0.01$; 95\% CI: 1.2-4.8); and (d) being female $(\mathrm{OR}=1.8, \mathrm{P}<0.05$; 95\% CI: 1.04-3.1). Significant interactions were found between "parents separated or divorced" with "low education" (OR $=5.5, \mathrm{P}<0.001$; 95\% CI: 2.3-13.0) as well as "financial situation not good or bad" with "lower social class" (OR = 3.9, P < 0.05; 95\% CI: 1.1-14.3). Furthermore, the OR of 3.2 (P < 0.05; 95\% CI: 1.1-9.8) reached significance for the interaction between "bad financial situation" and "being male". The OR for the interaction between "being female" with "not raised by both parents" is 2.3 (P < 0.05; 95\% CI: 1.2-4.6).

\section{Number of DSM-IV diagnoses in the total sample and suicide attempters}

Suicide attempt (Table 3) is strongly associated with psychopathology: including each disorder listed in Table 4, 91\% of all suicide attempters have at least one mental disorder with the vast majority being comorbid or multimorbid (79\%). The risk for suicide attempt is 3.5 times higher for subjects with two diagnoses than for subjects with no diagnosis, 6.4 times higher for those with three diagnoses and 18 times higher for those with more than three diagnoses.

\section{DSM-IV diagnoses in the total sample and in suicide attempters}

All examined DSM-IV diagnoses were significantly associated with suicide attempts, except for eating disorders. The highest univarate OR (7.8) was found for posttraumatic stress disorder (PTSD). Similarly high univariate ORs were found for dysthymia (OR = 7.5), specific phobia $(\mathrm{OR}=6.9$ ) and bipolar disorder $(\mathrm{OR}=5.4)$, as well as for the other anxiety disorders (ORs between 4.1 and 4.9). Slightly lower ORs were evident for illicit substance abuse/dependence and nicotine dependence (ORs of 3.5 and 3.3). An unexpectedly low OR of 2.2 emerged for major depressive episode as well as for alcohol abuse/dependence and somatoform disorder. Because of the substantial lifetime comorbidity, a subsequent multvariate analysis resulted in highly significant ORs for dysthymia and specific phobia (both OR = 3.6), panic attack and agoraphobia (both $\mathrm{OR}=2.3$ ) and illicit substance abuse/dependence $(\mathrm{OR}=2.2)$. 
In an attempt to reduce diagnostic complexity and reduce the risk of artefactual explanations, all 15 diagnoses with significant ORs included in Table 4 were summarized first into five different groups: any anxiety disorder, any bipolar disorder, any depressive disorder, any substance disorder and any somatoform disorder. In a second step the univariate and multivariate analyses were performed with mutually exclusive comorbidity groups. Highest univariate ORs (see upper part of Table 4) were found for "any anxiety disorder" (OR = 6.2), followed by "any bipolar disorder" $(\mathrm{OR}=5.4)$ and "any depressive disorder" $(\mathrm{OR}=3.4)$. In the multivarate analysis the highest OR emerges for any anxiety disorder (OR of 4.3), followed by any substance disorder $(\mathrm{OR}=2.2)$ and any depressive disorder $(\mathrm{OR}=2.1)$. The lower part of Table 5 shows that subjects with comorbidity of all five diagnostic groups have the highest multivariate OR (49.2). In summary, "any anxiety disorder” is present in all comorbidity patterns with significant ORs and the ORs increase with the number of diagnoses.

\section{Discussion}

The major aims of this study were to determine the prevalence and sociodemographic correlates of suicidal behaviours in a fairly large community sample of adolescents and young adults and to examine psychopathological associations with suicidal behaviours, focusing on specific DSM-IV diagnoses and the critical role of comorbidity. Prevalence and sociodemographic correlates There were no major surprises with regard to either the lifetime prevalence of suicide attempts or biosocial and sociodemographic correlates. In relatively good agreement with other community surveys (e.g. Lewis et al. 1988; Kienhorst et al. 1995) - given the considerable differences in methods - we found that the lifetime prevalence for attempted suicide in 14 - to 24 -year-olds was $2.3 \%$, with women $(3.1 \%)$ having twice the rate of men (1.5\%). Higher prevalence rates were reported only by Andrews and Lewinsohn (1992): 7.1\% with a female/male ratio of 3:1. A possible explanation for that might be that Andrews and Lewinsohn used questions in their interview that could have increased the likelihood of a positive response, e.g. "Have you ever tried to kill yourself or done anything that could have killed you?”. With regard to sociodemographic variables, we confirmed the findings of clinical and non-clinical studies conducted predominantly with adults (Kienhorst et al. 1995). Several partly interrelated variables were significantly related to suicide attempts. Among these the most powerful multivariate factors were: parents separated or divorced, not being raised by both parents, lower social class, bad financial situation, low education attainment, dropping out of school and being female.

\section{The role of specific mental disorders}

The two, at first sight, slightly puzzling findings concerning the examination of specific mental disorders, were: (a) that virtually all diagnoses examined - except for eating disorders - were at least moderately associated with suicide attempts; and (b) major depressive episodes (MDE) are not among the top ten diagnoses significantly associated with suicide attempts. Regarding single diagnoses, PTSD, dysthymia and specific phobias revealed the highest univariate odds ratios (close to or above 7), followed by bipolar affective disorders and several anxiety disorders (OR of 5.4 to 4.1), whereas substance use disorders, MDE, somatoform and eating disorders were at the end of the spectrum. Thus, anxiety disorders dominate the picture much more than depressive disorders. The multivariate analyses 
generally confirmed this overall picture, characterized by a strong dominance of anxiety disorders, with highly significant multivariate ORs for specific phobia (OR = 3.6), but also for dysthymia (OR = 3.6), as well as slightly elevated odds for panic attack and agoraphobia (both $\mathrm{OR}=2.3$ ) and for illicit substance use disorders $(\mathrm{OR}=2.2)$.

\section{Anxiety disorders}

The finding that among adolescents and young adults all DSM-IV anxiety disorders examined, and not only panicattack- related disorders, are strongly associated with suicide attempts goes beyond previous findings that have suggested that panic-related anxiety disorders play a more critical role in suicide attempts than previously thought. Those disorders have particularly pointed to the critical role of panic attacks and panic disorder (Bronisch and Wittchen 1994; Lepine et al. 1993; Petronis et al. 1990; Weissman et al. 1989), and less so to other anxiety disorders such as phobias and PTSD. Posttraumatic stress disorder, a condition that has up to now been rarely investigated in previous adolescent surveys, was found to be among the most strongly related conditions $(\mathrm{OR}=7.8)$ for suicide attempts. This confirms the observation of De Wilde et al. (1992) that stressful life events in suicide attempters were characterized by significantly more traumatic events such as periods of physical and sexual abuse. However, it still remains unclear why all phobias and especially specific phobias turned out to be so strongly associated with suicide attempts. We assume, in conjunction with our comorbidity pattern analyses (discussed below), that symptomatology and avoidance patterns of specific phobias might constitute important antecedent vulnerability factors for subsequently more severe psychopathology and the initiation of suicide attempts.

\section{Affective disorders}

In light of the above-mentioned studies that have fairly consistently reported close associations between MDE and suicidal behaviour (Andrews and Lewinsohn 1992; Brent et al. 1993; Breslau et al. 1991; Garrison et al. 1993; Garnefski and Diekstra 1995; Levy and Deykin 1989; Lewis et al. 1988; Joffe et al. 1988; Velez and Cohen 1988), the low OR for MDE and the considerably higher OR for dysthymia and bipolar disorders in our study requires further comments and discussion. Several reasons may account for this finding: 1. Unlike some of the previous studies, we examined the relative contribution of MDE for suicide attempts, using the odds ratio as a statistical measure taking into account the base rate, and thus controlled for chance findings. Although we found, in agreement with previous studies, that $46.5 \%$ of all suicide attempters had a MDE, it is also prevalent in subjects with no suicide attempts (prevalence 13\%), resulting in a moderate relative risk of 2.2 for suicide attempters. We assumed an inflated high association because our diagnostic instrument, the M-CIDI, assesses suicide attempts exclusively within the assessment module for MDE. Thus, only those acknowledging periods of at least 2 weeks duration with continuously depressed mood, low energy or loss of interest were asked the suicide questions. Thus, we can assume that, at least in fairly young respondents, major depression does not play such a significant role as a risk factor for suicide attempts than other affective disorders, particularly dysthymia. 2. The substantially higher risk associated with dysthymia, as compared with MDE, might be related to the longer duration of symptomatology and especially the increased hopelessness typically associated with this condition. We speculate, based on further in-depth analyses, that individuals experiencing depressive feelings and hopelessness over such a long stretch of time may feel that their suffering will never end, whereas individuals with shorter major depressive episodes may feel that their mood will revert to premorbid levels after a time. 3. Another likely hypothesis for explaining the high association of dysthymia may be that adolescents' dysthymia will progress to major depression later in their lives (Kovacs et al. 1993). 4. 
Although the lifetime prevalence for DSM-IV bipolar disorder (including hypomania and bipolar disorder NOS) is still fairly low (1.5\%) in our young sample (resulting in less stable estimates and associations), we confirm this disorder to be an important risk factor for suicide attempts (OR $=5.4 ; 14.8 \%$ of suicide attempters). Brent et al. (1993) found the bipolar spectrum disorder among $17.9 \%$ of adolescent suicide victims (OR $=9.0)$, and Arato et al. (1988) and Barraclough et al. (1974) reported a prevalence of $20 \%$ for bipolar disorder in their group of suicide victims. Rihmer et al. (1990) found 46\% with bipolar-II depression among 100 suicide victims with primary major depression. Lewinsohn et al. (1995a) compared adolescents with a history of major depression and a never-mentally- ill group with bipolar subjects. The subjects with bipolar disorder showed significantly more suicide attempts, higher rates of functional impairment and higher rates of comorbidity, particularly with anxiety and disruptive behaviour disorders. These data support the view that bipolar disorder is not uncommon among subjects with suicide behaviour, and that suicidal behaviour is a common complication of bipolar disorder. Impulsivity might possibly be regarded as a link between bipolar disorder and suicidal behaviour. Increased impulsivity plays an important role in suicide attempt and suicide execution (Crumley 1981; Epstein et al. 1973; Kashden et al. 1993), and also in individuals with bipolar disorder (Pössl and von Zerssen 1990). Substance use disorders revealed only modest associations with suicide attempts, ranging between an OR of 2.2 for alcohol abuse/dependence, 3.5 for illicit substance use disorders and 3.3 for nicotine dependence. In the multivariate model only illicit substance use disorders (OR of 2.2) remained significant. These findings are generally consistent with studies by Brent et al (1993). Similarly modest associations (2.2) were found for somatoform disorders (pain disorder or undifferentiated somatization disorder) with $28.5 \%$ of suicide attempters (compared with 12.2\% in the total sample) fulfilling criteria for this disorder. Somatization disorder, almost never studied as a risk factor for suicidal behaviour, has been reported, to our knowledge, only by Joffe et al. (1988).

\section{The role of comorbidity and comorbidity patterns}

Given the existence of a wide spectrum of lifetime and cross-sectional comorbidity patterns in our community sample of 14- to 24-year-olds and particularly the infrequency of pure disorders among suicide attempters, the evaluation of comorbidity is a tricky issue. Because of the high comorbidity rates, even in our fairly young community sample, and the low number of suicide attempters with only one disorder $(n=8)$, there were not enough cases in our study to compare pure anxiety and depressive disorder with comorbid cases to determine the exact OR for every single disorder. Whereas in the total sample $49.2 \%$ of all respondents were affected by at least one mental or substance use disorder, among those attempting suicide at least once in their life, $90.6 \%$ had at least one lifetime disorder. Among these, only $11.4 \%$ had a pure disorder, $17.0 \%$ had two, $17.0 \%$ three and $45.2 \%$ of all suicide attempters in our study had four or more DSM-IV diagnoses examined, compared with only $5.3 \%$ in the total sample. Thus, the relative risk for attempting suicide is nearly 3.5 times higher in those with two, 6.4 times higher in those with three and 18.4 times higher for subjects with four or more diagnoses as compared with subjects with no diagnosis. This raises the question of whether the increased risk for suicide attempts is simply a function of number of diagnoses, or more generally the complexity or severity of psychopathology, or whether there are critical combinations of diagnoses that can be held responsible for the elevated risk of suicide attempts. In an attempt to reduce both the complexity of these comorbidity patterns and the risk of artefactual associations, we first summarized the single diagnoses into five major diagnostic groups of "any anxiety disorder, any bipolar, any depressive disorder, any somatoform disorder and any eating disorder”, before forming mutually exclusive groups of diagnostic comorbidity patterns. Table 5 shows seven comorbidity patterns (with at least four 
subjects) out of 17 different comorbidity patterns of the suicide attempters. The lifetime comorbidity pattern of any anxiety, any depressive and any substance use disorder was the most frequent combination found in $11(15.7 \%)$ subjects. The findings of our final main multivariate odds ratio analysis allows for two main interpretations: 1 . In all significant comorbidity-pattern groups, comorbidity between anxiety and depressive disorders is involved. We could identify only seven comorbid suicide attempters without any anxiety disorder (12.5\%), with four of them having a depressive disorder and a substance use disorder (see Table 5) and the other three having different comorbidity patterns of three and four mental disorders, respectively. This suggests that depressive disorders are primarily associated with suicide attempts when they are comorbid with anxiety disorders. 2. Comorbidity with multiple disorders is associated with the highest risk for suicide attempts, especially when anxiety and depressive disorders are involved. Although suicide attempts in adolescence are embedded in a complex network of various relevant psychopathological, psychosocial and developmental risk factors, our findings document the important role of comorbidity for suicide attempts, especially comorbidity of anxiety and depressive disorders as well as comorbidity with a wide spectrum of other multiple disorders. Our cross-sectional lifetime analysis does not yet answer the essential question of why and how comorbidity contributes to suicide attempts because the described associations are based on the assessment of the lifetime occurrence of DSM-IV disorders and suicide attempts. Therefore, the suicide attempts may not have occurred at the same time as the disorder in question. The data thus far allow for various speculations of numerous potentially likely "pathways" (early trauma related as in PTSD sufferers, impulsivity as in bipolar sufferers, anxiety/arousal vulnerability as in anxiety disorders, etc.). A simpler explanation could be that the more psychiatric disorders the individual has, the more he or she suffers and the greater is the likelihood for suicide attempt. As a prospective longitudinal study, we hope that some of these hypotheses can be investigated further in more detail as part of the subsequent waves of the EDSP investigation.

Table 1 Prevalence rates of suicidal ideation and siucide attempts ( $n=3021$, weighted)

\begin{tabular}{|c|c|c|c|c|c|c|}
\hline \multirow[t]{2}{*}{ CIDI-M items } & \multicolumn{2}{|c|}{ Total } & \multicolumn{2}{|c|}{ Male } & \multicolumn{2}{|c|}{ Female } \\
\hline & $N$ & Rates/100 (SD) & $N$ & Rates/100 (SD) & $N$ & Rates $/ 100$ (SD) \\
\hline Suicide ideas ${ }^{a}$ & 307 & $10.2(0.30)$ & 119 & $8.0(0.27)$ & 188 & $12.3(0.33)$ \\
\hline Continuous wish to die & 204 & $6.8(0.25)$ & 67 & $4.5(0.21)$ & 137 & $8.9(0.29)$ \\
\hline Concrete plans for suicide & 130 & $4.3(0.20)$ & 48 & $3.2(0.18)$ & 82 & $5.4(0.23)$ \\
\hline
\end{tabular}

"Thoughts must occur continually over a period of 2 weeks 
Table 2 Sociodemographic distribution of the respondents $(n=3021)$ and the suicide attempters $(n=70)$; weighted)

\begin{tabular}{|c|c|c|c|c|c|c|c|c|c|}
\hline & \multicolumn{4}{|l|}{ Total } & \multicolumn{2}{|l|}{ Male } & \multicolumn{2}{|l|}{ Female } & \multirow{3}{*}{$\begin{array}{l}\text { OR: } \\
\text { univariate } \\
(95 \% \mathrm{CI})\end{array}$} \\
\hline & \multicolumn{2}{|c|}{ Respondents } & \multicolumn{2}{|c|}{$\begin{array}{l}\text { Suicide } \\
\text { attempters }\end{array}$} & \multirow{2}{*}{$\begin{array}{l}\begin{array}{l}\text { Respon- } \\
\text { dents }\end{array} \\
\text { Rates/100 }\end{array}$} & \multirow{2}{*}{$\begin{array}{l}\begin{array}{l}\text { Suicide } \\
\text { attempters }\end{array} \\
\text { Rates } / 100\end{array}$} & \multirow{2}{*}{$\begin{array}{l}\begin{array}{l}\text { Respon- } \\
\text { dents }\end{array} \\
\text { Rates/100 }\end{array}$} & \multirow{2}{*}{$\begin{array}{l}\begin{array}{l}\text { Suicide } \\
\text { attempters }\end{array} \\
\text { Rates/100 }\end{array}$} & \\
\hline & $N$ & Rates/100 & $N$ & Rates/100 & & & & & \\
\hline Gender & 3021 & 100 & 70 & 100 & 49.4 & 32.9 & 50.6 & 69.7 & $1.7^{*}(1.02-2.9)$ \\
\hline \multicolumn{10}{|l|}{ Age (years) } \\
\hline $14-17$ & 921 & 30.5 & 17 & 24.4 & 31.1 & 10.8 & 29.9 & 30.8 & ns. \\
\hline $18-21$ & 993 & 32.9 & 25 & 35.6 & 31.8 & 37.2 & 33.9 & 34.9 & ns. \\
\hline $22-24$ & 1107 & 36.6 & 28 & 40.0 & 37.1 & 52.2 & 36.2 & 34.3 & ns. \\
\hline \multicolumn{10}{|c|}{ Type of education (currently or completed) } \\
\hline Low: "Hauptschule" & 332 & 11.0 & 13 & 19.0 & 12.5 & 30.6 & 9.5 & 13.5 & $2.0 *(1.1-3.8)$ \\
\hline $\begin{array}{l}\text { Middle: "Realschule"/ } \\
\text { "Fachhochschule" }\end{array}$ & 701 & 23.2 & 14 & 19.9 & 20.8 & 7.7 & 25.5 & 25.7 & ns. \\
\hline $\begin{array}{l}\text { High: "Gymnasium"/ } \\
\text { University }\end{array}$ & 1973 & 65.3 & 39 & 55.6 & 66.3 & 61.7 & 64.3 & 52.8 & ns. \\
\hline Dropout & 15 & 0.5 & 4 & 5.5 & 0.4 & 0.0 & 0.6 & 8.1 & {$\left[41.7^{* * *}(7.0-249.5)\right]$} \\
\hline \multicolumn{10}{|c|}{ Current living arrangement } \\
\hline With parents & 1922 & 63.6 & 40 & 56.4 & 68.5 & 62.6 & 58.8 & 53.4 & ns \\
\hline Alone/with friends & 698 & 23.1 & 24 & 34.7 & 21.8 & 29.8 & 24.4 & 37.1 & ns. \\
\hline With partner & 288 & 9.5 & 3 & 4.0 & 7.9 & 0.0 & 11.1 & 5.8 & n.s. \\
\hline With spouse & 113 & 3.7 & 3 & 4.9 & 1.8 & 7.7 & 5.7 & 3.6 & n.s. \\
\hline \multicolumn{10}{|c|}{ Subjectrve financial situation } \\
\hline Very bad/bad & 248 & 8.2 & 13 & 18.9 & 9.4 & 40.7 & 7.1 & 8.7 & $2.3 *(1.1-4.1)$ \\
\hline Not good or bad & 847 & 28.0 & 25 & 36.1 & 27.9 & 14.6 & 28.2 & 46.3 & ns. \\
\hline Good/very good & 1926 & 63.7 & 32 & 44.9 & 62.7 & 44.7 & 64.8 & 45.0 & ns. \\
\hline \multicolumn{10}{|l|}{ Social class } \\
\hline Low & 230 & 7.6 & 13 & 18.8 & 8.6 & 16.4 & 6.6 & 19.9 & $2.8^{* * *}(1.5-5.3)$ \\
\hline Middle & 1785 & 59.1 & 40 & 56.4 & 57.3 & 60.4 & 60.8 & 54.5 & ns. \\
\hline Upper & 950 & 31.4 & 17 & 24.8 & 32.8 & 23.1 & 30.9 & 25.6 & ns. \\
\hline \multicolumn{10}{|l|}{ Family developement } \\
\hline Parents separated/divorced & 752 & 24.9 & 42 & 59.4 & 24.3 & 60.4 & 25.5 & 59.0 & $4.1^{* * *}(2.5-6.7)$ \\
\hline Not raised by both parents & 548 & 18.1 & 29 & 40.7 & 17.1 & 35.1 & 19.2 & 43.3 & $2.9 * * *(1.8-4.8)$ \\
\hline Maternal death & 66 & 2.2 & 2 & 2.2 & 2.1 & 6.9 & 2.3 & 0.0 & n.s. \\
\hline Patemal death & 150 & 5.0 & 5 & 7.0 & 5.5 & 9.1 & 4.5 & 6.0 & n.s. \\
\hline
\end{tabular}

"Concerning the comparison between total Suicide attempters and Respondents

$P \leq 0.05 ; * P \leq 0.01 ; * * * P \leq 0.001$

Table 3 Number of DSM-IV diagnoses of the total sample $(n=$ $3021)$ and the suicide attempters $(n=70$; weighted)

\begin{tabular}{|c|c|c|c|c|c|c|}
\hline \multirow{2}{*}{$\begin{array}{l}\text { No. of } \\
\text { DSM-IV } \\
\text { diagnoses }\end{array}$} & \multicolumn{2}{|c|}{ Total sample } & \multicolumn{2}{|c|}{$\begin{array}{l}\text { Suicide } \\
\text { attempters }\end{array}$} & \multicolumn{2}{|c|}{ Unvariate } \\
\hline & $N$ & Rates/100 & $N$ & Rates/100 & OR & $(95 \% \mathrm{CI})$ \\
\hline 0 & 1536 & 50.8 & 7 & 9.4 & & \\
\hline 1 & 788 & 26.1 & 8 & 11.4 & n.5. & \\
\hline 2 & 365 & 12.1 & 12 & 17.0 & $3.5^{* t *}$ & $(1.3-9.1)$ \\
\hline 3 & 171 & 5.6 & 12 & 17.0 & $6.4^{\text {t*t* }}$ & $(2.4-16.9)$ \\
\hline$>3$ & 161 & 5.3 & 32 & 45.2 & $18.4^{\text {t+*t }}$ & $(7.8-43.6)$ \\
\hline
\end{tabular}


Table 4 DSM-TV diagnoses in the total sample $(n=3021)$ and suicide attempters $(n=70$; weighted). PTSD posttraumatic stress disorder, GAD generalized anxiety disorder; $O C D$ obsessive-compulsive disorder

\begin{tabular}{|c|c|c|c|c|c|c|c|c|}
\hline \multirow[t]{2}{*}{ DSM-IV diagnoses } & \multicolumn{2}{|c|}{ Total sample } & \multicolumn{2}{|c|}{$\begin{array}{l}\text { Suicide } \\
\text { attempters }\end{array}$} & \multicolumn{2}{|c|}{ Univariate } & \multicolumn{2}{|c|}{ Multivariate } \\
\hline & $N$ & $\%$ & $N$ & $\%$ & OR & $95 \% \mathrm{CI}$ & OR & $95 \% \mathrm{CI}$ \\
\hline PTSD & 40 & 1.3 & 8 & 11.9 & $7.8^{*+*}$ & $(3.4-17.9)$ & n.s. & \\
\hline Dythymia & 91 & 3.0 & 19 & 27.5 & $7.5^{* \star *}$ & $(4.2-13.4)$ & $3.6^{* * *}$ & $(1.8-7.1)$ \\
\hline Simple phobia & 69 & 2.3 & 11 & 16.0 & $6.9 * * *$ & (3.3-14.1) & $3.6^{* *}$ & $(1.6-8.2)$ \\
\hline Bipolar disorder & 54 & 1.8 & 10 & 14.8 & $5.4^{* * *}$ & $(2.6-11.2)$ & n.s. & \\
\hline Panic attack & 131 & 4.3 & 16 & 23.1 & $4.9 * * *$ & $(2.7-8.9)$ & $2.3^{*}$ & $(1.1-4.7)$ \\
\hline $\mathrm{GAD}$ & 24 & 0.8 & 5 & 6.5 & $4.9 * * *$ & $(1.7-13.9)$ & n.s. & \\
\hline Social phobia & 106 & 3.5 & 14 & 19.9 & $4.4^{*+*}$ & $(2.3-8.3)$ & n.s. & \\
\hline$O C D$ & 22 & 0.7 & 4 & 5.3 & $4.4^{*+*}$ & $(1.4-13.8)$ & n.s. & \\
\hline Agoraphobia ${ }^{a}$ & 236 & 7.8 & 22 & 30.8 & $4.1^{* * *}$ & $(2.4-7.0)$ & $2.3^{* *}$ & $(1.2-4.3)$ \\
\hline Tllicit substance abuse/dependence & 138 & 4.6 & 14 & 20.1 & $3.5^{* * *}$ & $(1.9-6.6)$ & $2.2^{*}$ & $(1.1-4.6)$ \\
\hline Nicotine dependence & 568 & 18.8 & 36 & 51.7 & $3.3^{* * *}$ & $(2.0-5.3)$ & n.s. & \\
\hline Major depressive episode & 393 & 13.0 & 33 & 46.5 & $2.2^{* * *}$ & $(1.4-3.6)$ & n.s. & \\
\hline Alcohol abuse/dependence & 481 & 15.9 & 25 & 35.0 & $2.2^{* * *}$ & $(1.3-3.6)$ & n.s. & \\
\hline Somatoform disorder & 370 & 12.2 & 20 & 28.5 & $2.2^{* * *}$ & $(1.3-3.8)$ & n.s. & \\
\hline Eating disorder ${ }^{c}$ & 91 & 3.0 & 6 & 8.0 & n.s. & & n.s. & \\
\hline
\end{tabular}

Without panic disorder, syndrom or diagnosis

b Undifferentiated somatization disorder or pain disorder

'Bulimia or anorexia

Table 5 Comorbidity of the five diagnostic groups in the total sample $(n=3021)$ and suicide attempters $(n=70$; weighted)

\begin{tabular}{|c|c|c|c|c|c|c|c|c|}
\hline & \multicolumn{2}{|c|}{$\begin{array}{l}\text { Total } \\
\text { sample }\end{array}$} & \multicolumn{2}{|c|}{$\begin{array}{l}\text { Suicide } \\
\text { attempters }\end{array}$} & \multicolumn{2}{|c|}{ Univariate } & \multicolumn{2}{|c|}{ Multivariate } \\
\hline & $N$ & $\%$ & $N$ & $\%$ & OR & $95 \% \mathrm{CI}$ & OR & $95 \% \mathrm{CI}$ \\
\hline \multicolumn{9}{|l|}{ Single diagnostic groups } \\
\hline Any anxiety disorder" & 489 & 16.2 & 45 & 63.3 & $6.2^{* 4 *}$ & $(3.8-10.3)$ & $4.3^{* * *}$ & $(2.5-7.4)$ \\
\hline Any bipolar disorder & 54 & 1.8 & 10 & 14.8 & $5.4^{*+* t}$ & $(2.6-11.2)$ & n.s. & \\
\hline Any depressive disorder & 445 & 13.8 & 42 & 59.8 & $3.4^{* * *}$ & $(2.1-5.5)$ & $2.1^{* *}$ & $(1.2-\quad 3.6)$ \\
\hline Any substance disorder ${ }^{d}$ & 872 & 28.9 & 43 & 61.6 & $2.8^{* * *}$ & $(1.7-4.6)$ & $2.2^{* *}$ & $(1.3-3.6)$ \\
\hline Any somatoform disorder & 370 & 12.2 & 20 & 28.5 & $2.2^{* * *}$ & $(1.3-3.8)$ & n.s. & \\
\hline \multicolumn{9}{|c|}{ Comorbiaity of mutually exchusive diagnostic groups } \\
\hline $\begin{array}{l}\text { Anxiety, bipolar disorder, depression, } \\
\text { substance abuse and somatoform disorder }\end{array}$ & 6 & 0.2 & 4 & 5.2 & $28.8^{*+*}$ & $(5.6-148.4)$ & $49.2^{*+*}$ & $(9.4-257.8)$ \\
\hline $\begin{array}{l}\text { Anxiety, depression and substance } \\
\text { abuse disorder }\end{array}$ & 47 & 1.6 & 11 & 16.0 & $7.5^{* * *}$ & $(5.6-15.5)$ & $11.6^{* * *}$ & $(5.4-24.8)$ \\
\hline Anxiety, depression and somatoform disorder & 20 & 0.7 & 4 & 5.4 & $4.6^{* *}$ & $(1.5-14.4)$ & $7.8^{* * *}$ & $(2.4-25.3)$ \\
\hline $\begin{array}{l}\text { Anxiety, depression, substance abuse and } \\
\text { somatoform disorder }\end{array}$ & 24 & 0.8 & 4 & 6.2 & $4.3^{* *}$ & $(1.5-12.3)$ & $7.3^{* * *}$ & $(2.5-21.7)$ \\
\hline Anxiety and substance abuse disorder & 103 & 3.4 & 8 & 11.1 & $3.3 * 4$ & $(1.5-7.4)$ & $5.5^{* * *}$ & $(2.4-12.6)$ \\
\hline Anxiety and depression disorder & 50 & 1.7 & 5 & 7.5 & n.s. & & $3.9 * * *$ & $(1.5-10.2)$ \\
\hline Depression and substance abuse disorder & 87 & 2.9 & 4 & 6.0 & n.s. & & n.s. & \\
\hline
\end{tabular}

NOTE: All combinations of the five diagnostic groups which oc- b Bipolar-I disorder, bipolar-II disorder

cur in the group of the suicide attempters and to which applies c Major depression episode, dysthymia

$N>3$ were included in the analysis

" Panic attack, agoraphobia syndrom/diagnosis without panic dis-

dAlcohol abuse/dependence, illicit substance abuse/dependence,

obsessive-compulsive disorder, posttraumatic stress disorder

\section{References}

- American Psychiatric Association (1994) Diagnostic and statistical manual of mental disorders (DSM-IV), 4th edn. American Psychiatric Press, Washington, DC

- Andrews JA, Lewinsohn PM (1992) Suicidal attempts among older adolescents: prevalence and cooccurrence with psychiatric disorders. J Am Acad Child Adolesc Psychiatry 31: 655662

- $\quad$ Arato M, Demeter E, Rihmer Z, Somogyi E (1988) Retrospective psychiatric assessment of 200 suicides in Budapest. Acta Psychiatr Scand 77: 454-456 
- Barraclough B, Bunch J, Nelson B, Sainsbury P (1974) A hundred cases of suicide: clinical aspects. Br J Psychiatry 125: 355-373

- Brent DA, Joshua A, Perper JA et al. (1993) Psychiatric risk factors for adolescent suicide: a case-control study. J Am Acad Child Adolesc Psychiatry 32 (3): 521-529

- Breslau N, Davis GC, Andreski P (1991) Migraine, psychiatric disorders, and suicide attempts: an epidemiologic study of young adults. Psychiatry Res 37: 11-23

- Bronisch T (1992) Prospective long-term follow-up of suicide attempters. In: Crepet P, Ferrari G, Platt S, Bellini M (eds) Suicidal behaviour in Europe: recent research findings. John Libbey CIC, Rome, pp 177-182

- Bronisch T, Wittchen H-U (1994) Suicidal ideation and suicide attempts: comorbidity with depression, anxiety disorders, and substance abuse disorders. Eur Arch Psychiatry Clin Neurosci 244: 93-98

- Crumley FE (1981) Adolescent suicide attempts and borderline personality disorder: clinical features. South Med J 74: 546-549

- Diekstra RFW (1993) The epidemiology of suicide and parasuicide. Acta Psychiatr Scand 371 (Suppl): 9-20

- Dubow EF, Kausch DF, Blum MC, Reed J, Bush E (1989) Correlates of suicidal ideation and attempts in a community sample of junior high and high school students. J Clin Child Psychol 18: 158-166

- Epstein LC, Thomas CB, Shaffer JW et al. (1973) Clinical prediction of physician suicide based on medical student data. J Nerv Ment Dis 156: 19-29

- Garnefski N, Diekstra RFW (1995) Suicidal behaviour and the cooccurrence of behavioural, emotional and cognitive problems among adolescents. Arch Suicide Res 1: 243-260

- Garrison CZ, McKeown RE, Valois RF, Vincent ML (1993) Aggression, substance use and suicidal behaviors in high school students. Am J Public Health 83: 179-184

- Harkavy Friedman JMH, Asnis GM, Boeck M, DiFiore J (1987) Prevalence of specific suicidal behaviors in a high school sample. Am J Psychiatry 144: 1203-1206

- Johnson J, Weissman M, Klerman GL (1990) Panic disorder, comorbidity, and suicide attempts. Arch Gen Psychiatry 47: 805-808

- Joffe RT, Offord DR, Boyle MH (1988) Ontario Child Health Study: suicidal behavior in youth age 12-16 years. Am J Psychiatry 145: 1420-1422

- Kashden J, Fremouw WJ, Callahan TS, Franzen MD (1993) Impulsivity in suicidal and nonsuicidal adolescents. J Abnorm Child Psychol 21: 339-353

- Kessler RC, McGonagle KA, Zhao S, Nelson CB, Hughes M, Eshleman S, Wittchen H-U, Kendler KS (1994) Lifetime and 12-month prevalence of DSM-III-R psychiatric disorders in the United States: results from the National Comorbidity Survey. Arch Gen Psychiatry 51: 819

- Kienhorst IWM, Wilde EJ de, Diekstra RFW (1995) Suicidal behaviour in adolescents. Arch Suicide Res 1: 185-209

- Kovacs M, Goldston D, Gatsonis C (1993) Suicidal behaviors and childhood-onset depressive disorders: a longitudinal investigation. J Am Acad Child Adolesc Psychiatry 32: 8-20

- Lepine JP, Chignon JM, Teherani M (1993) Suicide attempts in patients with panic disorder. Arch Gen Psychiatry 50: 144-149

- Levy JC, Deykin EY (1989) Suicidality, depression, and substance abuse in adolescence. Am J Psychiatry 146: 1462-1467

- Lewinsohn PM, Klein DN, Seeley JR (1995a) Bipolar disorder in a community sample of older adolescents: prevalence, phenomenology, comorbidity, and course. J Am Acad Child Adolesc Psychiatry 34: 454-463

- Lewinsohn PM, Rohde P, Seeley JR (1995b) Adolescent psychopathology: III. The clinical consequences of comorbidity. J Am Acad Child Adolesc Psychiatry 34 (4): 510-519

- Lewis SA, Johnson J, Cohen P, Garcia M, Velez CN (1988) Attempted suicide in youth: its relationship to school achievement, educational goals, and socioeconomic status. J Abnorm Child Psychol 16: 459-471 
- Pfister H, Wittchen H-U (1995) M-CIDI computer program. Max Planck Institute of Psychiatry, Clinical Institute, Munich

- Petronis KR, Samuels JF, Moscicki EK, Anthony JC (1990) An epidemiologic investigation of potential risk factors for suicide attempts. Soc Psychiatry Psychiatr Epidemiol 25: 193-199

- Pössl J, von Zerssen D (1990) A case history analysis of the 'manic type' and the 'melancholic type' of premorbid personality in affectively ill patients. Eur Arch Psychiatry Neurol Sci 239: 347-355

- $\quad$ Rihmer Z, Barsi J, Arato M, Demeter E (1990) Suicide in subtypes of primary major depression. J Affect Disord 18: 221-225

- Schmidtke A, Bille-Brahe U, DeLeo D et al. (1996) Attempted suicide in Europe: rates, trends and sociodemographic characteristics of suicide attempters during the period 1989-1992. Results of the WHO/EURO multicentre study on parasuicide. Acta Psychiatr Scand 93: 327338

- Shaffer D, Vieland V, Garland A, Rojas M, Underwood M, Busner C (1990) Adolescent suicide attempters: response to suicide-prevention programs. J Am Med Assoc 264: 31513155

- Smith K, Crawford S (1986) Suicidal behavior among "normal” high school students. Suicide Life Threat Behav 16: 313-325

- Spirito A, Brown L, Overholser J, Fritz G (1989) Attempted suicide in adolescence: a review and critique of the literature. Clin Psychol Rev 9: 335-363

- SPSS Incorporation (1997) SPSS für Windows, version 7.5.2G

- Velez CN, Cohen P (1988) Suicidal behavior and ideation in a community sample of children: material and youth reports. J Am Acad Child Adolesc Psychiatry 27: 349-356

- Weissman MM, Klerman GL, Markowitz JS, Ouellette R (1989) Suicidal ideation and suicide attempts in panic disorder and attacks. N Engl J Med 321: 1209-1214

- Wilde J de, Kienhorst CWM, Rene FW et al. (1992) The relationship between adolescent suicidal behavior and life events in childhood and adolescence. Am J Psychiatry 149: 45-51

- Wittchen HU, Pfister H (1997) Instruktionsmanual zur Durchführung von DIA-X-Interviews. Swets and Zeitlinger B.V., Frankfurt

- Wittchen H-U, Nelson CB, Lachner G (1998) Prevalence of mental disorders and psychosocial impairments in adolescents and young adults. Psychol Med 28: 109-126

- Wittchen H-U, Lachner G, Wunderlich U, Pfister H (1998) Test-Retest Reliability of the computerized DSM-IV version of the Munich-Composite International Diagnostic Interview (M-Cidi). Soc Psychiatry Epidemiol (in press)

- Wittchen H-U, Beloch E, Garczynski E, Holly A, Lachner G, Perkonigg A, Pfütze E-M, Schuster P, Vodermaier A, Vossen Z, Wunderlich U, Zieglgänsberger S (1995) Münchener Composite International Diagnostic Interview (M-CIDI, paper-pencil 2.2, 2/95). Max Planck Institute of Psychiatry, Clinical Institute, Munich (self-print)

- World Health Organization (1990) Composite International Diagnostic Interview (CIDI). WHO, Geneva

- World Health Organization (1991) International Classification of Diseases (ICD-10). WHO, Geneva 